\title{
Estimation of the genetic parameters of sexual dimorphism of body weight in 'label' chickens and Muscovy ducks
}

\author{
Sandrine Mignon-Grasteau ${ }^{\mathrm{a} *}$, Catherine Beaumont ${ }^{\mathrm{a}}$, \\ Jean-Paul Poivey ${ }^{\mathrm{b}}$, Hubert de Rochambeau ${ }^{\mathrm{b}}$ \\ a Station de recherches avicoles, Institut national de la recherche agronomique, \\ domaine de l'Orfrasière, 37380 Nouzilly, France \\ b Station d'amélioration génétique des animaux, Institut national de la recherche \\ agronomique, chemin de Borde-Rouge BP 27, Auzeville, \\ 31326 Castanet-Tolosan cedex, France
}

(Received 12 August 1997; accepted 8 June 1998)

\begin{abstract}
The genetic parameters of sexual dimorphism of body weight were estimated in samples of 16190 chickens and 11328 Muscovy ducks. A multivariate animal model was used, and weights of males and females were treated as different traits. Heritabilities were estimated for males and females, respectively, at $0.28 \pm 0.04$ and $0.43 \pm 0.04$ for body weight at 8 weeks in chickens $(B W 8)$, and in ducks at $0.40 \pm 0.04$ and $0.51 \pm 0.04$ for body weight at 6 weeks $(B W 6)$ and $0.33 \pm 0.05$ and $0.67 \pm 0.05$ for weight gain between 6 weeks and slaughter $(W G)$. The estimated genetic correlations between sexes were 0.84 for $B W 8$ in chickens, and 0.85 and 0.73 for $B W 6$ and $W G$ in ducks, respectively. Maternal heritabilities were generally higher in males than in females. Heritabilities of sexual dimorphism were estimated as 0.08 for $B W 8$ in chickens, and at 0.13 and 0.18 for $B W 6$ and $W G$ in Muscovy ducks, respectively. Sexual dimorphism in both species was highly and positively correlated with traits of males (between 0.65 and 0.84 ), and slightly and positively correlated with growth potential of females (between 0.13 and 0.25 ). (C) Inra/Elsevier, Paris
\end{abstract}

sexual dimorphism/ Muscovy duck/ chicken/ body weight/ genetic parameters

Résumé - Estimation des paramètres génétiques du dimorphisme sexuel du poids chez le poulet label et le canard de Barbarie. Les paramètres génétiques du dimorphisme sexuel du poids ont été estimés chez le poulet label et le canard de Barbarie respectivement sur 16190 et 11328 animaux. Un modèle animal multicaractère a été utilisé et les caractères mâles et femelles considérés comme différents. Les

* Correspondence and reprints

E-mail: grasteau@tours.inra.fr 
héritabilités des caractères considérés ont été estimées pour les mâles et les femelles, respectivement, à $0,28 \pm 0,04$ et $0,43 \pm 0,04$ pour le poids à 8 semaines $(B W 8)$ chez le poulet, $0,40 \pm 0,04$ et $0,51 \pm 0,04$ pour le poids à 6 semaines $(B W 6)$ chez le canard et $0,33 \pm 0,05$ et $0,67 \pm 0,05$ pour le gain de poids entre 6 semaines et l'abattage ( $W G)$ chez le canard. Les corrélations génétiques estimées entre sexes étaient inférieures à 1 (respectivement 0,84 pour $B W 8,0,85$ pour $B W 6$ et 0,73 pour $W G$ ). Les héritabilités maternelles estimées étaient le plus souvent plus élevées chez les mâles que chez les femelles. L'héritabilité du dimorphisme sexuel a été estimée à 0,08 pour $B W 8,0,13$ pour $B W 6$ et 0,18 pour $W G$. Pour les deux espèces, le dimorphisme sexuel apparaît corrélé positivement et fortement au caractère mâle (avec des corrélations génétiques variant entre 0,65 et 0,84 ) et positivement mais faiblement au caractère femelle (avec des estimations comprises entre 0,13 et 0,25 ). (c) Inra/Elsevier, Paris

dimorphisme sexuel / canard de Barbarie / poulet / poids / paramètres génétiques

\section{INTRODUCTION}

The difference in weight between males and females, hereafter called sexual dimorphism (and denoted $\Delta$ ), is particularly marked in poultry. For example, male Muscovy ducks are $40 \%$ heavier than females at slaughtering age, and $65 \%$ heavier when adults [18]. In chickens, where the difference is smaller, males are $15-20 \%$ heavier than females $[33,36]$. The body composition of males and females also differs considerably $[12,18,28]$.

This dimorphism poses several problems, as already noted by Pilla [26] for Muscovy ducks. Breeding requirements differ with sex; male Muscovy ducks are slaughtered and jointed at 12 weeks, whereas females are slaughtered at 10 weeks, and are not heavy enough to be jointed. However, slaughter of females cannot be delayed because the breast, drumsticks and thighs approach maximum size at this age, and thereafter females begin to deposit fat. It is thus necessary to rear animals keeping the sexes separate. In chickens, outliers are damaged during automated processing [17]. These losses are particularly high for French label-type chickens, which are slaughtered from 81 days of age. This high quality product accounted for $15 \%$ of the consumption of chicken in France in 1994. 'Label' chickens originate from crosses between slow growing meat-type lines and are selected for increased egg number or breast angle but not for increased body weight. This selection permits slaughtering at an older age (from $81 \mathrm{~d}$ of age) at the same carcass weight as conventional birds [8]. Carcasses exhibit a high meat yield and a moderate degree of fatness. The specifications for this type of production include access to open air, feed based mainly on grain, low density of rearing $\left(<11\right.$ animals $\left./ \mathrm{m}^{2}\right)$, and distance between the farm and the slaughterhouse $(<100 \mathrm{~km}$ or $<2 \mathrm{~h}$ of transport $)$.

According to the results of L'Hospitalier et al. [19] in meat-type poultry lines, sexual dimorphism at $42 \mathrm{~d}$ increased markedly with selection from $249 \mathrm{~g}$ in 1972 to $318 \mathrm{~g}$ in 1985 , while the ratio of male to female body weight $(R)$ remained almost unchanged, from 1.207 to 1.182 . These differences suggest a genetic influence on sexual dimorphism.

The aim of this study was therefore to estimate genetic parameters of sexual dimorphism and to investigate the possibility of modifying it by selection. 
This involved estimation of genetic parameters of growth traits in both sexes, to evaluate whether the same genes were expressed in males and females. The results of this analysis were used to calculate genetic parameters of $\Delta$ and of the ratio of the trait expressed in males to the trait expressed in females. Finally, genetic correlations between sexual dimorphism and certain economically important traits were estimated to predict how they might change following selection for sexual dimorphism. This study was performed in two species whose sexual dimorphism is very different, i.e. the Muscovy duck and the chicken. For the latter, a line dedicated to the production of 'label' chickens was chosen. In fact, even if selection for decreased sexual dimorphism was detrimental to body weight, it could be performed in these lines. No valid estimates of genetic parameters for sexual dimorphism are currently available for label chickens or Muscovy ducks.

\section{MATERIALS AND METHODS}

\subsection{Animals and description of traits}

A total of 16190 chickens from 385 sires and 1766 dams of a slow growing meat-type line were studied, comprising six generations of a line measured for body weight at 8 weeks $(B W 8)$ and selected for number of eggs laid over 22 weeks $(E N)$. Breast angle at 8 weeks $(B A)$ and body weight at $1 \mathrm{~d}$ $(B W 1)$ were also recorded in the last generation on 2236 and 2243 animals, respectively.

A total of 11328 Muscovy ducks from 204 sires and 772 dams were included in the analysis. They had been produced from the last three generations of a line that had been selected for 11 generations for increased body weight at 6 weeks $(B W 6)$ and weight gain between 6 weeks and slaughter $(W G)(12$ weeks for males and 10 weeks for females) as well as for the weight of the fatty liver of males after $13 \mathrm{~d}$ of cramming $(L W)$. Body weight at $1 \mathrm{~d}$ of age $(B W 1)$ was also measured in the last generation on 4138 animals.

Body weight was considered as a sex-limited trait so that male and female traits were distinguished in the analysis, as suggested by Falconer [11]. For example, four traits were analysed in ducks: $B W 6_{m}, B W 6_{f}, W G_{m}, W G_{f}$ where the subscripts ' $m$ ' and ' $f$ ' stand for male and female, respectively.

\subsection{Analysis model}

The analysis model was:

$$
y_{i j k}=h_{i}+a_{j}+m_{k}+e_{i j k} \text { with } \operatorname{cov}(\mathbf{a}, \mathbf{m}) \neq 0
$$

where $y_{i j k}$ is the performance of the $j$ th animal from the $k$ th dam, reared in the $i$ th hatch, $a_{j}$ the direct genetic effect of the $j$ th animal, $m_{k}$ the maternal genetic effect from the $k$ th dam, $e_{i j k}$ the residual of the $j$ th animal from the $k$ th dam, reared in the $i$ th hatch and $\operatorname{cov}(\mathbf{a}, \mathbf{m})$ the covariance matrix between the vector of direct genetic effects (a) and the vector of maternal genetic effects (m). The vectors $\mathbf{a}, \mathbf{m}$ and $\mathbf{e}$ were considered to be normally distributed. 
The (co)variances were estimated by REML using VCE3.2 software $[13,24]$ using finite difference procedures.

In the first analysis, the genetic parameters of the selected traits were estimated, i.e. $B W 6_{m}, B W 6_{f}, W G_{m}, W G_{f}$ and $L W$ for ducks and $B W 8_{m}$, $B W 8_{f}$ and $E N$ for chickens. All the traits were included in the analysis, in order to avoid bias due to selection. A second analysis was performed to determine the genetic correlations between sexual dimorphism and other traits of economic importance. It included all the aforementioned traits and $B W 1$ in ducks, $B W 1$ or $B A$ in chickens. Because of lack of convergence, cov $(\mathbf{a}, \mathbf{m})$ had to be set at $\mathbf{0}$ for this analysis.

\subsection{Estimation of genetic parameters}

The genetic parameters of sexual dimorphism were estimated in the second step. Heritability was calculated using the classic formula of (co)variance for difference, as already used by Chapuis et al. [7]. The genetic correlations between sexual dimorphism and the other traits were computed in a similar way.

The heritability of the ratio of the male trait to the female trait $(R)$ was approximated using Sutherland's formula [34]:

$$
h^{2}(R)=\frac{h_{m}^{2} C_{m}^{2}+h_{f}^{2} C_{f}^{2}-2 r_{g}(m, f) C_{m} C_{f} h_{m} h_{f}}{C_{m}^{2}+C_{f}^{2}-2 r_{p}(m, f) C_{m} C_{f}}
$$

where $h_{m(f)}^{2}$ was the heritability of the male (female) trait, $r_{g}(m, f)$ and $r_{p}(m, f)$ the genetic and phenotypic correlations between traits in males and females, and $C_{m(f)}$ the phenotypic coefficient of variation for the male (female) trait.

Using Pearson's formula [25], the genetic correlation between the trait expressed in one sex, e.g. males, and the ratio was approximated as:

$$
r_{g}\left(B W_{m}, R\right)=\frac{h_{m} C_{m}-r_{g}(m, f) h_{f} C_{f}}{\left(h_{f}^{2} C_{f}^{2}+h_{m}^{2} C_{m}^{2}-2 r_{g}(m, f) h_{f} h_{m} C_{f} C_{m}\right)^{1 / 2}}
$$

\section{RESULTS}

The elementary statistics are summarized in table $I$. There was no dimorphism at $1 \mathrm{~d}$ of age in either species, and sexual dimorphism increased with age. This increase was proportionally much more pronounced for $\Delta$ than for $R$.

\subsection{Genetic parameters of analysed traits}

Estimated heritabilities of growth traits were moderate or high in both species, as shown in table $I I a$ for ducks and $I I b$ for chickens. For all traits, the estimates were higher for females than for males by 53.6, 27.5 and $103.0 \%$ for $B W 8$ in chickens, $B W 6$ and $W G$ in ducks, respectively. According to the 
Table I. Elementary statistics of analysed traits.

\begin{tabular}{llcccc}
\hline Species & Traits & $\begin{array}{c}\text { Males } \\
\text { Mean } \pm \text { S.D. }\end{array}$ & $\begin{array}{c}\text { Females } \\
\text { Mean } \pm \text { S.D. }\end{array}$ & $\begin{array}{c}\Delta \\
\text { (in \% of the } \\
\text { female trait) }\end{array}$ & \\
\hline Muscovy duck & $B W 1(\mathrm{~g})^{1}$ & $48.8 \pm 4.9$ & $48.6 \pm 4.7$ & 0.00 & 1.00 \\
& $B W 6(\mathrm{~g})^{1}$ & $1834 \pm 304$ & $1269 \pm 203$ & 44.44 & 1.44 \\
& $W G(\mathrm{~g})^{2}$ & $2663 \pm 317$ & $1086 \pm 153$ & 145.21 & 2.45 \\
& $L W(\mathrm{~g})^{3}$ & $462 \pm 96$ & - & - & - \\
\hline \multirow{2}{*}{ Chicken } & $B W 1(\mathrm{~g})^{1}$ & $46.7 \pm 40$ & $46.0 \pm 3.8$ & 0.01 & 1.02 \\
& $B W 8(\mathrm{~g})^{1}$ & $1468 \pm 260$ & $1235 \pm 181$ & 18.87 & 1.10 \\
& $B A(\text { grade })^{4}$ & $85.1 \pm 6.2$ & $84.7 \pm 5.2$ & 0.00 & 1.00 \\
& $E N^{5}$ & - & $92.0 \pm 25.0$ & - & - \\
\hline
\end{tabular}

${ }^{1} B W_{x}$ : body weight at age $x ;{ }^{2} W G$ : weight gain between 6 weeks and slaughtering age ${ }^{3} L W$ : liver weight; ${ }^{4} B A$ : breast angle; ${ }^{5} E N$ : egg number.

estimated standard errors, and assuming the asymptotic normal distribution reached, these differences appeared to be highly significant. Estimated maternal heritabilities were low and decreased with age.

Estimated genetic correlations between sexes were high and decreased with age in both species. The correlations between sexes were lower for maternal genetic effects than for direct genetic effects. The estimated correlation between direct and maternal genetic effects was negative for all traits.

\subsection{Genetic parameters of sexual dimorphism}

In ducks, there was little difference in the heritabilities of sexual dimorphism and ratio. They were estimated as 0.13 and 0.11 for $B W 6$ and 0.18 and 0.27 for $W G$. In chickens, both estimates were equal to 0.08 .

Dimorphism appeared to be highly and positively correlated with body weight of males, and positively but moderately correlated with body weight of females in both species (table III $a, b)$. In ducks, this trend was more pronounced for $W G$, the trait showing the greatest sexual dimorphism. For ratios, estimates of genetic correlation with body weight at the same age were positive in males and negative in females, except for $W G_{m}$ which was slightly negatively correlated with the ratio for $W G$.

The estimate of the genetic correlation between sexual dimorphism at 6 weeks and sexual dimorphism for weight gain was very low $(-0.02)$. Moreover, in ducks the genetic correlation between $\triangle B W 6$ and $W G$ and the genetic correlation between $\triangle W G$ and $B W 6$ were moderate, ranging from -0.15 to 0.15 .

Genetic correlations between $\Delta$ and $L W$ or $B W 1$, and $R$ and $L W$ or $B W 1$ were moderate in ducks. In chickens, $B A$ was the trait most positively correlated with both sexual dimorphism and the ratio. 
Table IIa. Genetic parameters of traits analysed in Muscovy ducks.

\begin{tabular}{lccccc}
\hline Traits & $B W 6_{m}$ & $B W 6_{f}$ & $W G_{m}$ & $W G_{f}$ & $L W$ \\
\hline$B W 6_{m}$ & $\begin{array}{c}0.40 \pm 0.04 \\
(0.11 \pm 0.03)\end{array}$ & $\begin{array}{c}0.85 \\
0.51 \pm 0.04\end{array}$ & -0.23 & -0.17 & -0.25 \\
& & & & \\
$B W 6_{f}$ & 0.34 & $(0.09 \pm 0.02)$ & 0.04 & 0.12 & 0.05 \\
$W G_{m}$ & -0.44 & -0.33 & $(0.05 \pm 0.03)$ & 0.73 & -0.26 \\
$W G_{f}$ & -0.27 & -0.41 & 0.54 & $(0.09 \pm 0.05)$ & -0.24 \\
$L W$ & 0.32 & 0.31 & 0.02 & 0.17 & $(0.08 \pm 0.06)$ \\
\hline
\end{tabular}

Heritabilities are on the diagonal (maternal heritabilities in italics), genetic correlations above the diagonal, correlations for maternal effects below the diagonal.

Table IIb. Genetic parameters of traits analysed in chickens.

\begin{tabular}{lccc}
\hline Traits & $B W 8_{m}$ & $B W 8_{f}$ & $E N$ \\
\hline & $0.28 \pm 0.04$ & & \\
$B W 8_{m}$ & $(0.14 \pm 0.02)$ & 0.84 & -0.17 \\
$B W 8_{f}$ & 0.60 & $0.43 \pm 0.04$ & -0.30 \\
$E N$ & 0.14 & $(0.10 \pm 0.02)$ & $0.37 \pm 0.08$ \\
& & & $(0.06 \pm 0.05)$ \\
\hline
\end{tabular}

Heritabilities are on the diagonal (maternal heritabilities in italics), genetic correlations above the diagonal, correlations for maternal effects below the diagonal.

\section{DISCUSSION}

\subsection{Choice of the model of analysis}

The existence of maternal effects in poultry has been suspected for many years (see reviews by Chambers [6] in fowls, Ricard et al. [27] in ducks) as heritabilities were generally higher when based on dam than on sire components. Koerhuis and Thompson [15] showed that their effects were significant on body weight in broilers. Following the protocol described by Koerhuis and Thompson [15], we found that fitting maternal effects and/or correlation between maternal genetic effect and direct genetic effect significantly increased the log-likelihood in both species. A model including environmental maternal effect was also fitted, leading to a slightly greater likelihood as in Koerhuis and Thompson [15], but as it could lead to overparametrization [7], we preferred to fit the model described above. 
Table IIIa. Genetic correlations between sexual dimorphism $(\Delta)$ and male or female $B W 6^{1}, W G^{2}$ and $L W^{3}$ and between the ratio of male to female traits $(R)$ and male or female $B W 6, W G$ or $L W$ in Muscovy ducks.

\begin{tabular}{rrrrrrr}
\hline & & $B W 6_{m}^{*}$ & $B W 6_{f}^{*}$ & $W G_{m}$ & $W G_{f}$ & \multicolumn{1}{c}{$L W$} \\
\hline \multirow{2}{*}{$B W 6$} & $\Delta$ & 0.72 & 0.25 & -0.10 & -0.15 & 0.38 \\
& $R$ & 0.14 & -0.40 & -0.12 & -0.07 & 0.01 \\
\multirow{3}{*}{$W$} & $\Delta$ & 0.10 & 0.15 & 0.84 & 0.23 & -0.17 \\
& $R$ & 0.22 & 0.20 & -0.19 & -0.81 & 0.13 \\
\hline
\end{tabular}

${ }^{1} B W 6$ : body weight at 6 weeks; ${ }^{2} B W$ : weight gain between 6 weeks and slaughtering age; ${ }^{3} L W$ : liver weight. ${ }^{*} m$ and $f$ subscripts stand for male and female, respectively.

Table IIIb. Genetic correlations between sexual dimorphism $(\Delta)$ and male or female $B W 8^{1}, B W 1^{2}, E N^{3}$ and $B A^{4}$ and between the ratio of male to female traits $(R)$ and male or female $B W 8, B W 1, E N$ and $B A$ in chickens.

\begin{tabular}{ccccccc}
\hline & & $B W 1$ & $B W 8_{m}^{*}$ & $B W 8_{f}^{*}$ & $E N$ & $B A$ \\
\hline$B W 8$ & $\Delta$ & -0.09 & 0.65 & 0.13 & 0.11 & 0.40 \\
& $R$ & -0.13 & 0.23 & 0.34 & 0.24 & 0.35 \\
\hline
\end{tabular}

${ }^{1} B W 8$ : body weight at 8 weeks; ${ }^{2} B W 1$ : body weight at 1 day; ${ }^{3} E N$ : egg number. ${ }^{4} B A$ : breast angle. ${ }^{*} m$ and $f$ subscripts stand for male and female, respectively.

\subsection{Genetic parameters of growth traits in both sexes}

As observed by Merritt [23] and Ayoub et al. [2] in small groups of broilers and by Chapuis et al. [7] in a large sample of data on turkeys, heritability appears to be higher for female body weight than for male body weight. Higher residual variance and lower additive genetic variance were observed for male traits. The former could be related to competition between males, and to a higher frequency of leg disorders, which affect growth. The latter may be due to the more precocious growth of females [18]. At a given age, they are more mature than males $[12,18]$ and their body composition, e.g. the percentage of fat tissue, also differs. This could also contribute to increased heritability of growth traits of females, as this trait is very heritable [3].

The means of estimates of heritability of maternal genetic effects for both sexes were similar to those observed by Koerhuis and Thompson [15] when analysing data of males and females together. These maternal effects most probably originated from the genetic and environmental determinism of dam size (and consequently of egg size) and egg quality [1, 16]. Extrachromosomal inheritance may also contribute to the genetic part of maternal effects [16]. It is of note that maternal heritability tended to be lower in females for juvenile body weight, as already suspected in Muscovy ducks by Ricard et al. [28] and observed in quails by Aggrey and Cheng [1] and in turkeys by Chapuis et al. [7]. It might be explained by the greater precocity of females. Their growth might depend on the maternal effects for a shorter time and be more dependent upon 
their own genes. This hypothesis is consistent with the decrease in maternal effects with age that was observed between $B W 6$ and $W G$.

Koerhuis and Thompson [15] have already reported that estimates of the correlation between direct and maternal genetic effects were negative in poultry. They showed that this result was not due to an environmental dam-offspring covariance.

Our estimates of genetic correlations between growth traits in both sexes show that the genes controlling body weight in both sexes differ. Lower estimates were obtained on a small number of animals with Henderson's methods, i.e. 0.59 at 10 weeks by Buvanendran [5] in a meat-type chicken line and 0.69 at 40 weeks by Singh et al. [32] in a layer-type chicken line. Using REML in layer-type chicken lines, Hagger [14] and Tixier-Boichard et al. [35] observed higher values for this correlation at 40 weeks $(0.84$ and 0.71 , respectively). However, the last two studies were performed on chickens of a very different genetic background at an older age, i.e. after sexual maturity. The genes involved are probably not the same as in our case. Using REML, Chapuis et al. [7] also found that the genetic correlation between sexes decreased with age. The mean values were 0.92 at 12 weeks and 0.87 at 16 weeks (i.e. slaughtering age for females and males, respectively).

The differences between sexes in feed and water intake (as observed by McCarthy and Siegel [20], Marks [21, 22]) and the hormonal regulation of growth $[4,29,37]$ contribute to the existence of sexual dimorphism.

As in our study, the genetic correlation between sexes was estimated at a given age in all studies, i.e. probably at different physiological ages, as females are more precocious than males. This could at least partly explain why this correlation is lower than one. In ducks, we found that the correlation between body weight of both sexes at 10 weeks was lower $(0.72)$ than the correlation between body weight of males at 12 weeks and body weight of females at 10 weeks $(0.81)$.

As heritability of body weight varied with sex, and as the genetic correlation between sexes differed from one, body weights of males and females should be treated as different traits in ducks and chickens.

\subsection{Genetic parameters of sexual dimorphism}

Our results show that heritabilities of $\Delta$ and $R$ were significantly higher than zero, and that it should be possible to modify sexual dimorphism by selection. It is of note that heritability is higher in ducks, where $\Delta$ is more important, than in label chickens. In ducks, heritability of $\Delta$ increases with age as observed by Chapuis et al. [7] in turkeys. Previous results performed on only a few animals and considering differences between family means of body weights of males and females lead to higher heritabilities of sexual dimorphism in chickens, between 0.17 and 0.27 at 4 and 8 weeks, respectively, for Buvanendran [5] and Singh et al. [33] and between 0.42 and 0.95 in Muscovy ducks [26].

It is important to know whether sexual dimorphism results only from a scale effect. If this was the case, heritabilities in both sexes would be equal and the genetic correlation between sexes would be equal to one. Heritability of the difference would not be equal to zero but heritability of the ratio would be. All our estimates of heritability of the ratio are higher than zero, which shows 
that sexual dimorphism cannot be attributed solely to a scale effect. Some of the genes controlling body weight in males and females differ. This difference is more marked for older animals as sexual hormones most probably play a more important role. The difference in precocity between the sexes may also interfere both in the direct and the maternal effects. It should therefore be possible to select for increased or decreased sexual dimorphism as performed in mice by Eisen and Hanrahan [9] and Schmidt [30]. They observed that the increase was more marked than the decrease and that body weight changed more for males than for females, as suggested by our estimates. No such experiment has yet been performed in poultry to our knowledge. For practical application both increase and decrease in sexual dimorphism could be envisaged. For example, in ducks, it might be useful to increase $\Delta$ in order to obtain lighter females that could be more easily sold while keeping male body weight constant. On the other hand, decreasing $\Delta$ could result in heavier females that could be jointed. Moreover, these estimated correlations also show that selection for increased body weight has most probably contributed to the augmentation in sexual dimorphism already suspected by Shaklee et al. [31] in turkeys.

According to the estimated genetic correlations, selecting for other traits $(B A$ and $E N$ in chickens and $L W$ in ducks) must have resulted in a modification of $\Delta$ and, to a smaller extent, $R$.

The correlation between the ratio of male to female body weight and sexual dimorphism was very high in chickens (0.98) which suggested concomitant evolution of both traits. In ducks, however, it was estimated at 0.78 and 0.38 for $B W 6$ and $W G$, respectively. In this case, a change in the ratio would not result in a similar evolution of $\Delta$. Essl [10] also found through simulation that selecting for a ratio would not necessarily result in a similar evolution of the difference.

\section{CONCLUSION}

This study shows that genetics plays a role in sexual dimorphism which cannot be attributed entirely to a scale effect. The heritability of sexual dimorphism shows that selection for this trait should be effective. According to the genetic correlations between sexual dimorphism and body weight of each sex, such selection should lead to asymmetrical evolution of both sexes.

\section{ACKNOWLEDGEMENTS}

We would like to thank those who made this work possible and the anonymous referees for their helpful comments on the manuscript.

\section{REFERENCES}

[1] Aggrey S.A., Cheng K.M., Animal model analyses and genetic (co)variances for growth traits in Japanese quail, Poultry Sci. 73 (1994) 1822-1828.

[2] Ayoub H., Khireldin M., Shalash S., Inheritance of body weight and breast length at 8 weeks of age in meat type strains of chicken, Ann. Génét. Sél. Anim. 12 (3) (1980) 281-290. 
[3] Becker W.A., Spencer J.V., Mirosh L.W., Verstrate J.A., Genetic variation of abdominal fat, body weight and carcass weight in a female broiler line, Poultry Sci. 63 (1984) 607-611.

[4] Burke W.H., Sharp P.J., Sex differences in body weight of chicken embryos, Poultry Sci. 68 (1989) 805-810.

[5] Buvanendran V., The heritability and genetic correlations of sexual dimorphism for 10-week weight in poultry, Br. Poultry Sci. 10 (1969) 321-325.

[6] Chambers J.R., Genetics of growth and meat production in chickens, in: Crawford R.D. (Ed.), Poultry Breeding and Genetics, Elsevier, vol. 22, 1990, pp. 599 643.

[7] Chapuis H., Ducrocq V., Tixier-Boichard M., Delabrosse Y., Multivariate restricted maximum likelihood estimation of genetic parameters for production traits in three selected strains, Genet. Sel. Evol. 28 (2) (1996) 197-215.

[8] Culioli J., Touraille C., Ricard F., Meat quality of 'label fermier' chicken in relation to production factors, in: 9th Eur. Poult. Conf., Glasgow, World Poult. Sci. Assoc., UK, 7-12 August, vol. 2, 1994, pp. 25-28.

[9] Eisen E., Hanrahan J.P., Selection for sexual dimorphism in body weight in mice, Aust. J. Biol. Sci. 25 (1972) 1015-1024.

[10] Essl A., Selection for a ratio of two traits: results of a simulation study, J. Anim. Breed. Genet. 106 (1989) 81-88.

[11] Falconer D.S., The problem of environment and selection, Am. Nat. 86 (1952) 293-298.

[12] Ganpule S.P., Ricard F.H., Influence of sex and age at slaughter on growth rate and carcass characteristics in chickens from four lines selected for fatness, Arch. Geflügelk. 52 (5) (1988) 200-204.

[13] Groeneveld E., REML VCE: a multivariate multi model restricted maximum likelihood (co)variance component estimation package, version 3.2, User's Guide, 1996.

[14] Hagger C., Genetic correlations between body weight of cocks and production traits in laying hens, and their possible use in breeding schemes, Poultry Sci. 73 (1994) 381-387.

[15] Koerhuis A., Thompson R., Models to estimate maternal effects for juvenile body weight in broiler chicken, Genet. Sel. Evol. 29 (3) (1997) 225-249.

[16] Lande R., Kirkpatrick M., Selection response in traits with maternal inheritance, Genet. Res. Camb. 55 (1990) 189-197.

[17] Lauras B., Kerharo A., Détermination des critères de non-qualité en production de dinde découpée, Sci. Tech. Avic. 7 (1994) 21-27.

[18] Leclercq B., Croissance et composition corporelle du canard de Barbarie, in: Sauveur B., de Carville H. (Eds.), Le canard de Barbarie, Inra, Paris, 1990, pp. 169 193.

[19] L'Hospitalier R., Bougon M., Le Menec M., Quemeneur P., Evolution des performances des poules reproductrices de type chair et de leur descendance, de 1962 à 1985, Bull. Inf. Station Exp. d'Aviculture de Ploufragan 26 (1986) 3-16.

[20] McCarthy J.C., Siegel P.B., A review of genetical and physiological effects of selection in meat-type poultry, Anim. Breed. Abstr. 51 (1983) 87-94.

[21] Marks H.L., The role of water intake on the sexual dimorphism for early growth of broilers, Poultry Sci. 65 (1985) 433-435.

[22] Marks H.L., Sexual dimorphism in broilers following periods of equal water and feed intake, Poultry Sci. 66 (1987) 381-389.

[23] Merritt E.S., Estimates by sex of genetic parameters for body weight and skeletal dimensions in a random bred strain of meat type fowl, Poultry Sci. 45 (1966) 118-125. 
[24] Neumaier A., Groeneveld E., Restricted maximum likelihood estimation of covariances in sparse linear models, Genet. Sel. Evol. 30 (1) (1998) 3-26.

[25] Pearson K., Mathematical contributions to the theory of evolution. On a form of spurious correlation which may arise when indices are used in the measurement of organs, Proc. Roy. Soc. London 60 (1897) 489-502.

[26] Pilla A.M., Possibilità di miglioramento genetico dell'anatra muschiata, Ann. Ist Sper. Zootec. 7 (2) (1974) 165-174.

[27] Ricard F.H., Leclercq B., de Carville H., Mise au point sur les caractéristiques et les méthodes d'élevage du Canard de Barbarie, Ann. Zootech. 32 (2) (1983) 189200.

[28] Ricard F.H., Marché G., Le Bihan-Duval E., Essai d'amélioration par sélection de la qualité de carcasse du poulet de chair, Prod. Anim. 17 (4) (1994) 445-458.

[29] Scanes C.G., Harvey S., Marsh J.A., King D.B., Hormones and growth in poultry, Poultry Sci. 63 (1984) 2062-2074.

[30] Schmidt T.A., Divergent selection for sexual dimorphism in mice-6 generations of selection, in: Annual meeting of the EAAP, Aarhus, National Institute of Animal Science, 16-19 August, 1993.

[31] Shaklee W.E., Knox C.W., Marsden S.J., Inheritance of sex differences of body weight in turkeys, Poultry Sci. 31 (1952) 822-825.

[32] Singh S.S., Khan A.G., Shrivastava P.N., Genetic correlations between sexual dimorphism in juvenile body weight and productive traits in White Leghorn chicken, Indian J. Poultry Sci. 14 (1) (1979) 43-46.

[33] Singh S.S., Verma S.K., Khan A.G., Shrivastava A.K., Studies in genetic variability in juvenile body weight and sexual dimorphism in layer type chicken, Indian J. Poultry Sci. 24 (4) (1989) 308-310.

[34] Sutherland T.M., The correlation between feed efficiency and rate of gain, a ratio and its denominator, Biometrics 21 (1965) 739-749.

[35] Tixier-Boichard M., Boichard D., Groeneveld E., Bordas A., Restricted maximum likelihood estimates of genetic parameters of adult male and female Rhode Island Red chickens divergently selected for residual feed consumption, Poultry Sci. 74 (1995) 1245-1252.

[36] Van der Horst F., L'élevage du poulet label jaune en sexes séparés, Sci. Tech. Avic. 7 (1994) 36-42.

[37] Vasilatos-Younken R., Scanes C.G., Growth hormones and insulin-like growth factors in poultry growth: required, optimal or ineffective? Poultry Sci. 70 (1991) 1764-1780. 